\title{
Ultrasound-Guided Fine-Needle Aspiration with or without Negative Pressure for Different Types of Thyroid Nodules
}

\author{
Qi Zhou' \\ Wenjun Wu' \\ Fang Wang ${ }^{2}$ \\ Xiaohua Gong' \\ Xiaojun Chen' \\ 'Department of Endocrinology and \\ Metabolism, The First Affiliated Hospital \\ of Wenzhou Medical University, \\ Wenzhou, Zhejiang, 325015, People's \\ Republic of China; ${ }^{2}$ Department of \\ Pathology, The First Affiliated Hospital of \\ Wenzhou Medical University, Wenzhou, \\ Zhejiang, 325015, People's Republic of \\ China
}

Correspondence: Xiaohua Gong; Xiaojun Chen

Department of Endocrinology and Metabolism, The First Affiliated Hospital of Wenzhou Medical University, Ouhai District, Wenzhou, Zhejiang, 3250I5,

People's Republic of China

Email gxhI204@I63.com; chenxiaojun dr@yeah.net
Object: To evaluate the effects of ultrasound-guided fine-needle aspiration with or without negative pressure (FNA+P or FNA-P) on diagnosis of thyroid nodules.

Methods: A prospective randomized study was performed. Patients $(\mathrm{n}=1374$, female $=1094$, $79.6 \%$, male $=280,20.4 \%$, age $=48.7 \pm 12.5 \mathrm{yr}$ ) with thyroid nodules were randomly divided into FNA-P $(\mathrm{n}=774,56.3 \%)$ and FNA+P $(600,43.7 \%)$ groups. Thyroid nodules were diagnosed by FNA-P or FNA+P, in the left $(n=640,46.6 \%)$ and right $(n=734,53.4 \%)$.

Results: The thyroid nodules were diagnosed as microcalcification $(n=751,54.7 \%)$, coarse calcification $(n=404,29.4 \%)$, peripheral calcification $(n=101,7.4 \%)$ and mixed micro + coarse calcification $(n=118,8.6 \%)$. Based on Bethesda classification criteria, the thyroid nodules were cataloged as type I ( $\mathrm{n}=217,15.8 \%)$, II $(\mathrm{n}=467,34.0 \%)$, III $(\mathrm{n}=151,11.0 \%)$, $\mathrm{V}(\mathrm{n}=333,24.2 \%)$, and VI $(\mathrm{n}=206,15.0 \%)$. There were no significant differences between experimental groups diagnosed by FNA-P or FNA+P.

Conclusion: The results suggest that fine-needle aspiration with or without negative pressure does not significantly affect the sensitivity of thyroid nodule diagnosis.

Keywords: thyroid nodules, ultrasound-guided fine-needle aspiration, negative pressure, diagnosis

\section{Introduction}

The epidemiological investigation has shown that the diagnosis of thyroid nodules, a common clinical disease, is $3-7 \%$ with palpation, $19-35 \%$ with the highdefinition ultrasound, and $8-65 \%$ with autopsy. ${ }^{1,2}$ The prevalence of thyroid nodules in different regions is different and affected by the race, age, sex, eating habits, living environment, genetics, and iodine nutritional status. Some thyroid nodules $(5-15 \%)$ develop to the thyroid cancer. ${ }^{3-5}$ The incidence of thyroid cancer is rapidly increasing on a global scale, but the specific reasons are unclear. According to the statistical analysis from the Shanghai Municipal Center for Disease Control and Prevention, the incidence of thyroid cancer among men in Shanghai in 2008 was 5.83 per 100,000, and the incidence of women was as high as 21.2 per 100,000 . The incidence of thyroid cancer has jumped to the fifth place among women who are prone to tumors. The Report on Incidence of Malignant Tumors in Beijing Residents issued by the Beijing Municipal Health Bureau in 2012 showed that, from 2000 to 2012, the incidence of thyroid cancer increased by $223.75 \%$, ranking the first among all types of cancer. Thyroid cancer was the most diagnosed cancer among women under 30 years of age in China in $2015 .^{6}$ 
Thyroid cancer not only seriously affects the physical health but also causes a heavy burden on mental and psychological conditions of patients. Therefore, it is necessary to accurately assess benign and malignant thyroid nodules. The color Doppler ultrasound is the preferred non-invasive examination for thyroid diseases with high value in the diagnosis of thyroid benign and malignant nodules. The malignant feature of thyroid nodules under ultrasound imaging includes solid hypoechoic, microcalcification, irregular edges, nodule aspect ratio $>1$, and cervical lymph node metastasis. ${ }^{7}$

Since 1980s, thyroid nodule biopsy has become the most accurate and efficient method to identify benign and malignant thyroid nodules. ${ }^{8}$ Ultrasound-guided fineneedle aspiration (US-FNA) has been used to diagnose thyroid nodules and cancers. ${ }^{9}$ Ultrasound risk stratification systems are also used for identification of papillary thyroid cancer. ${ }^{10,11}$ FNA without negative pressure (FNA-P) reduces the risk of blood contamination, but FNA with negative pressure $(F N A+P)$ increases the sensitivity of the biopsy results. ${ }^{12}$ In the present study, we have performed a randomized analysis of FNA with or without negative pressure to compare the effects of two methods for different types of thyroid nodules.

\section{Methods}

\section{Patients}

Between January 2016 and September 2020, 1374 patients were enrolled at The First Affiliated Hospital of Wenzhou Medical University for suspected thyroid nodules by FNA. The patients were randomly divided into two groups, fine-needle aspiration without negative pressure (FNA-P) and fine-needle aspiration with negative pressure $(\mathrm{FNA}+\mathrm{P})$ groups. The protocol of the study was conducted in accordance with the Declaration of Helsinki ${ }^{13}$ and approved by the ethics committee of The First Affiliated Hospital of Wenzhou Medical University (No. 2018-026). All patients signed the informed consent.

\section{US-FNA}

The tests of US-FNA with or without negative pressure (FNA+P or FNA-P) were performed under ultrasonographic guidance using SonoSite S-Cath color Doppler ultrasonic diagnostic apparatus, probe frequency 5-12 MHz. A $10-\mathrm{mL}$ syringe and a $23-\mathrm{G}$ needle were used in the FNA+P approach. The needle attached to a 10-
$\mathrm{mL}$ syringe with an approximately $3-\mathrm{mL}$ vacuum suction was inserted to the center of the mass under ultrasonographic guidance. Several passes through the nodule were performed with back-and-forth maneuver from different orientations and then released when the sample became visible in the hub of needle. The FNA-P approach was performed by simply inserting the needle to the center of the mass and waiting for the sample to collect in the hub of needle via capillary action. The operations were performed in the strict standards. The evaluations were performed using a multihead microscope, and the final decision was reached via consensus. The thyroid calcified nodules were divided into 4 categories, microcalcification, coarse calcification, peripheral calcification, and mixed calcification (micro + coarse calcification). ${ }^{14}$ The selected nodules are all calcified. The inclusion criteria included (1) thyroid nodules with calcification by ultrasound examination, and (2) the maximum diameter $>5 \mathrm{~mm}$. The exclusion criteria included (1) the maximum diameter of the nodule $<5 \mathrm{~mm}$, (2) the results of preoperative blood routine and coagulation function test suggesting abnormal coagulation function, (3) continuing to take preoperative anticoagulant drugs such as dabigatran and warfarin, and (4) with severe basic diseases.

\section{Diagnostic Criteria}

Cytology was based on Bethesda classification criteria, including type I (specimen cannot be diagnosed or unsatisfactory), type II (benign lesions), type III (follicular or atypical follicular lesions that cannot be clearly defined), type IV (follicular nodule/suspicious follicular nodule), type $\mathrm{V}$ (suspected malignant tumor) and type VI (malignant tumor). ${ }^{15}$

\section{Statistical Analysis}

SPSS19.0 statistical software was used for statistical analysis. McNemar test was used to compare the sensitivity, specificity and positive types of calcified nodules. $\mathrm{P}<0.05$ was set as the difference with the statistical significance.

\section{Results}

\section{Diagnostic Measurements with FNA-P or FNA+P}

There were 1374 patients with thyroid nodules included in this study, among whom 1094 were female (79.6\%), 
and 280 were male (20.4\%), with an age range of 12 to 90 years $(48.7 \pm 12.5 \mathrm{yr}), 564(41.0 \%) \geq 45 \mathrm{yr}$ and 810 $(59.0 \%)<45 y$. The patients were randomly divided into two groups, $774(56.3 \%)$ in the group of fine-needle aspiration without negative pressure (FNA-P) and 600 $(43.7 \%)$ in the group of fine-needle aspiration with negative pressure $(\mathrm{FNA}+\mathrm{P})$ (Table 1). By FNA-P or FNA+P, thyroid nodules were diagnosed in the left $(n=640,46.6 \%)$ and in the right $(n=734,53.4 \%)$ (Table 1).

\section{Pathological Diagnosis and Bethesda Classification}

The thyroid nodules were diagnosed as microcalcification $(\mathrm{n}=751,54.7 \%),{ }^{16,17}$ coarse calcification $(\mathrm{n}=404,29.4 \%),{ }^{18}$ peripheral calcification $(\mathrm{n}=101,7.4 \%)^{14}$ and mixed micro + coarse calcification $(\mathrm{n}=118,8.6 \%)$ (Table 2). Based on Bethesda classification criteria, the thyroid nodules were cataloged as type I $(n=217,15.8 \%)$, type II $(n=467,34.0 \%)$, type III $(\mathrm{n}=151,11.0 \%)$, type V $(\mathrm{n}=333,24.2 \%)$, and type

Table I Patient Grouping and Thyroid Nodule Position

\begin{tabular}{|c|c|c|c|c|}
\hline \multicolumn{5}{|c|}{ Patient Grouping } \\
\hline \multicolumn{2}{|c|}{ FNA+P } & \multicolumn{2}{|c|}{ FNA-P } & \multirow{2}{*}{$\begin{array}{l}\text { Total } \\
\text { n }\end{array}$} \\
\hline $\mathbf{n}$ & $\%$ & $\mathbf{n}$ & $\%$ & \\
\hline 600 & 43.7 & 774 & 56.3 & 1374 \\
\hline \multicolumn{5}{|c|}{ Position of Thyroid Nodules } \\
\hline \multicolumn{2}{|c|}{ Left } & \multicolumn{2}{|c|}{ Right } & Total \\
\hline $\mathbf{n}$ & $\%$ & $\mathbf{n}$ & $\%$ & $\mathbf{n}$ \\
\hline 640 & 46.6 & 734 & 53.4 & 1374 \\
\hline
\end{tabular}

VI ( $n=206,15.0 \%$ ) (Table 2, Figure 1). Bethesda type IV was not found in the diagnosed thyroid nodules.

\section{Comparison Between FNA-P and FNA+P Groups}

Different types of thyroid nodules diagnosed by FNA-P and FNA $+\mathrm{P}$ were compared (Table 3, Figure 1). In each calcification of thyroid nodules with small $(5-10 \mathrm{~mm})$ or large $(>10 \mathrm{~mm})$ size, patients in FNA-P and FNA+P groups were analyzed (Table 3). Patients in the small or large size groups were diagnosed as type I, II, III, $\mathrm{V}$ and VI by FNA-P or FNA+P. The P value in the small and large size groups was 0.445 and 0.711 in the microcalcification, 0.152 and 0.156 in the coarse calcification, 0.772 and 0.632 in the peripheral calcification, 1.000 and 0.794 in the mixed micro + coarse calcification, respectively, without significant difference. The data of this study were summarized in Figure 2. The results suggest that fine-needle aspiration with or without negative pressure does not significantly affect the sensitivity of thyroid nodule diagnosis.

\section{Discussion}

The ultrasound-guided fine needle aspiration (US-FNA) of thyroid nodule is a simple and safe procedure. Typically, the biopsy is performed under ultrasound guidance to ensure accurate placement of the needle within the thyroid nodule. FNA with negative pressure $(\mathrm{FNA}+\mathrm{P})$ is believed to increase the sensitivity of the biopsy results. ${ }^{19}$ Recently, a study has shown that negative pressure is not necessary for FNA to diagnosis of thyroid nodules. ${ }^{12}$ In our prospective randomized study, 1374 patients with thyroid nodules have been diagnosed using FNA with or without negative pressure. The results have shown no significant differences

Table 2 Classification of Thyroid Nodules

\begin{tabular}{|l|c|c|c|c|c|c|c|c|c|c|}
\hline \multirow{2}{*}{ Type } & \multicolumn{2}{|c|}{ Micro } & \multicolumn{2}{c|}{ Coarse } & \multicolumn{2}{c|}{ Peripheral } & \multicolumn{3}{c|}{ Mixed } & \multicolumn{2}{c|}{ Total } \\
\cline { 2 - 10 } & $\mathbf{n}$ & $\%$ & $\mathbf{n}$ & $\%$ & $\mathbf{n}$ & $\%$ & $\mathbf{n}$ & $\%$ & $\mathbf{n}$ & $\%$ \\
\hline $\mathrm{I}$ & 94 & 43.3 & 65 & 30.0 & 37 & 17.1 & 21 & 9.7 & 217 & 15.8 \\
II & 204 & 43.7 & 188 & 40.3 & 47 & 10.1 & 28 & 6.0 & 467 & 34.0 \\
III & $9 \mathrm{I}$ & 60.3 & 36 & 23.8 & 10 & 6.6 & 14 & 9.3 & 151 & 11.0 \\
V & 225 & 67.6 & 75 & 22.5 & 4 & 1.2 & 29 & 8.7 & 333 & 24.2 \\
VI & 137 & 66.5 & 40 & 19.4 & 3 & 1.5 & 26 & 12.6 & 206 & 15.0 \\
Total & $75 \mathrm{I}$ & 54.7 & 404 & 29.4 & 101 & 7.4 & 118 & 8.6 & 1374 & 100.0 \\
\hline
\end{tabular}

Notes: Cytology was based on Bethesda classification criteria. Type I: specimen cannot be diagnosed or unsatisfactory; Type II: benign lesions; Type III: follicular or atypical follicular lesions that cannot be clearly defined; Type V: suspected malignant tumor; Type Vl: malignant tumor.

Abbreviations: Micro, microcalcification; Coarse, coarse calcification; Peripheral, peripheral calcification; Mixed, mixed calcification (micro + coarse calcification). 


\section{Micro}

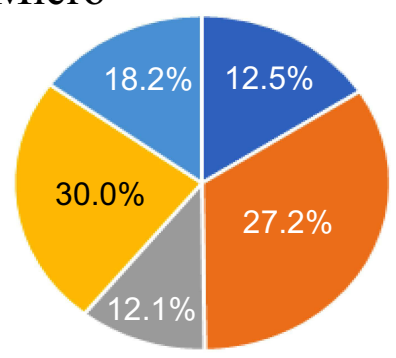

Coarse

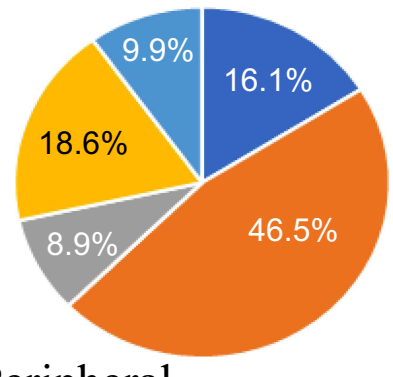

\section{Peripheral}

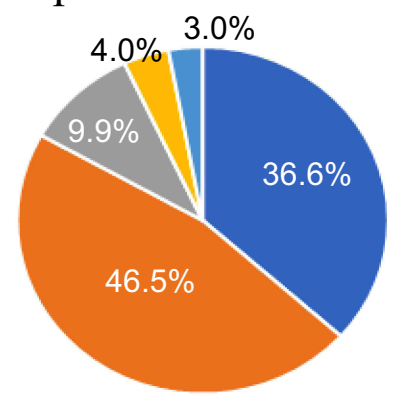

Mixed

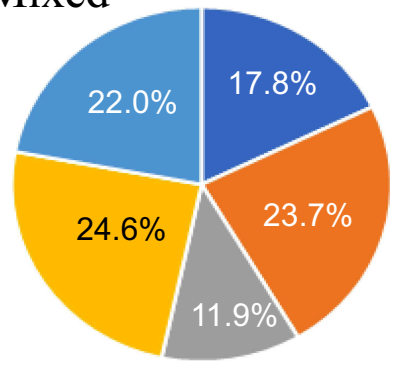

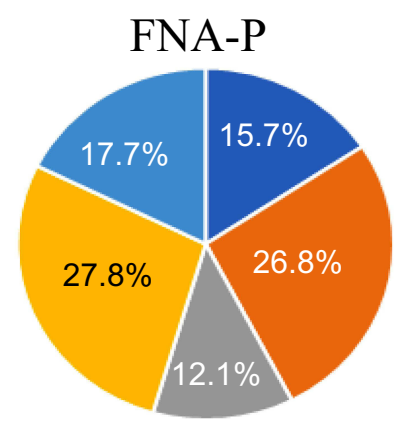
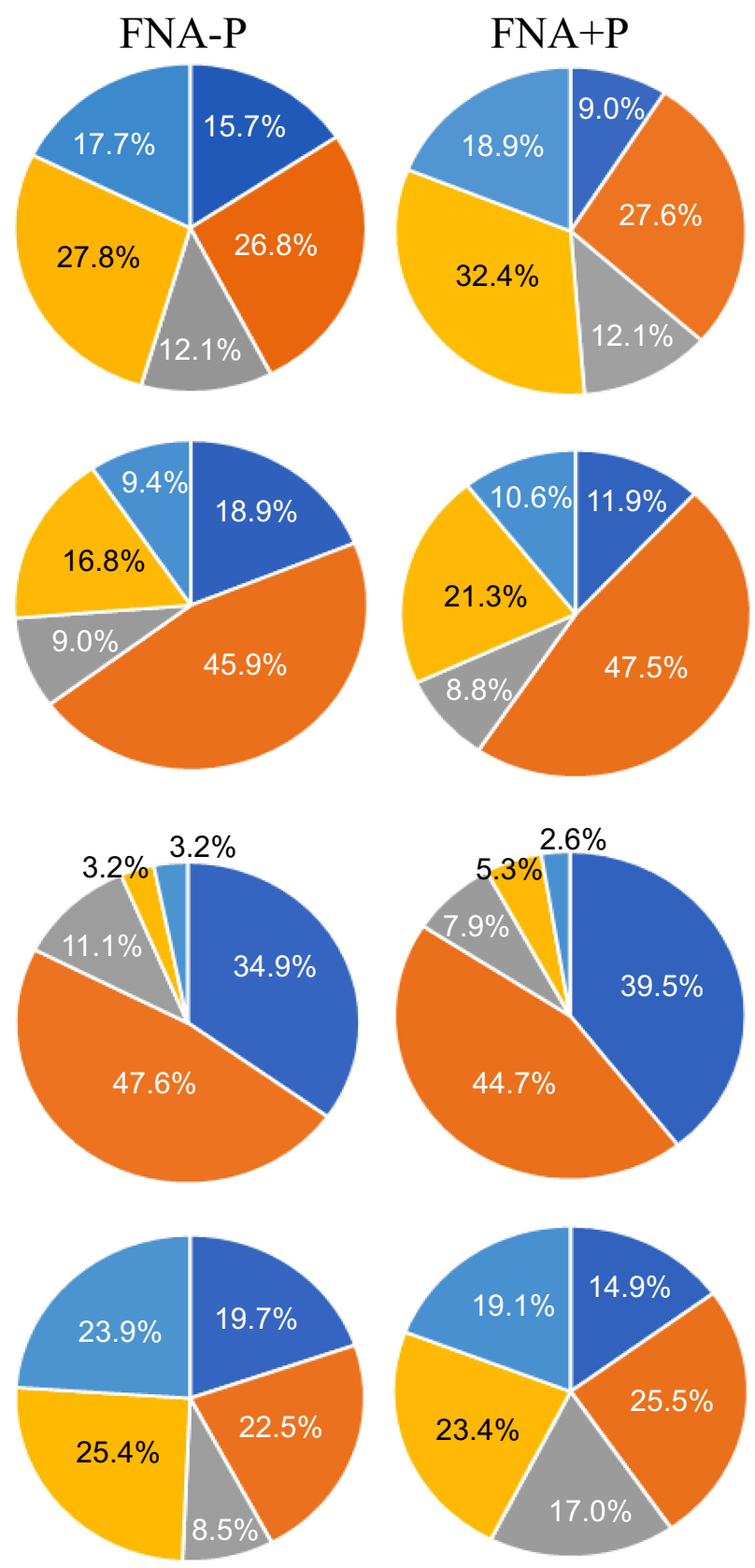

\section{\begin{tabular}{lllllll}
\hline & I & II & III & V & VI
\end{tabular}}

Figure I The percentages of calcifications and types of thyroid nodules cataloged based on Bethesda classification criteria.

Abbreviations: Micro, microcalcification; Coarse, coarse calcification; Peripheral, peripheral calcification; Mixed, micro + coarse calcification; FNA-P, fine-needle aspiration without negative pressure; FNA+P, fine-needle aspiration with negative pressure; I, type I; II, type II; III, type III; V, type V; VI, type VI.

between FNA $+\mathrm{P}$ and FNA-P groups in type I (specimen cannot be diagnosed or unsatisfactory), type II (benign lesions), type III (follicular or atypical follicular lesions that cannot be clearly defined), type $\mathrm{V}$ (suspected malignant tumor) and type VI (malignant tumor). In this study, we did not find Bethesda IV nodules in the fine needle aspiration, which may be because type IV is rare in small size nodules and the low incidence of follicular tumors. Our results match the Bethesda classification criteria, where the frequency of nodules is higher for categories $\mathrm{I}, \mathrm{V}$ and VI (total 54\%), and lower for category II (34\%). 
Table 3 Comparison of Different Types of Thyroid Nodules Diagnosed by FNA-P and FNA

\begin{tabular}{|c|c|c|c|c|c|c|c|c|c|c|c|c|c|c|}
\hline \multirow[t]{2}{*}{ Group } & \multirow[t]{2}{*}{ Size $(\mathbf{m m})$} & \multirow[t]{2}{*}{ Negative } & \multirow[t]{2}{*}{$\mathbf{n}$} & \multicolumn{2}{|c|}{ I } & \multicolumn{2}{|c|}{ II } & \multicolumn{2}{|c|}{ III } & \multicolumn{2}{|c|}{$\mathbf{v}$} & \multicolumn{2}{|c|}{ VI } & \multirow[t]{2}{*}{$\mathbf{P}$} \\
\hline & & & & $\mathrm{n}$ & $\%$ & $\mathrm{n}$ & $\%$ & $\mathrm{n}$ & $\%$ & $\mathrm{n}$ & $\%$ & $\mathrm{n}$ & $\%$ & \\
\hline \multirow[t]{4}{*}{ Micro } & \multirow[t]{2}{*}{$5-10$} & FNA-P & 258 & 48 & 18.6 & 55 & 21.3 & 37 & 14.3 & 75 & 29.1 & 43 & 16.7 & \multirow[t]{2}{*}{0.445} \\
\hline & & $\mathrm{FNA}+\mathrm{P}$ & 232 & 20 & 8.6 & 63 & 27.2 & 32 & 13.8 & 86 & 37.1 & 31 & 13.4 & \\
\hline & \multirow[t]{2}{*}{$>10$} & FNA-P & 138 & 14 & 10.1 & 51 & 37.0 & 11 & 8.0 & 35 & 25.4 & 27 & 19.6 & \multirow[t]{2}{*}{0.711} \\
\hline & & $F N A+P$ & 123 & 12 & 9.8 & 35 & 28.5 & II & 8.9 & 29 & 23.6 & 36 & 29.3 & \\
\hline \multirow[t]{4}{*}{ Coarse } & \multirow[t]{2}{*}{$5-10$} & FNA-P & 122 & 31 & 25.4 & 40 & 32.8 & 13 & 10.7 & 27 & 22.1 & II & 9.0 & \multirow[t]{2}{*}{0.152} \\
\hline & & $\mathrm{FNA}+\mathrm{P}$ & 80 & 14 & 17.5 & 33 & 41.3 & 8 & 10.0 & 18 & 22.5 & 7 & 8.8 & \\
\hline & \multirow[t]{2}{*}{$>10$} & FNA-P & 122 & 15 & 12.3 & 72 & 59.0 & 9 & 7.4 & 14 & 11.5 & 12 & 9.8 & \multirow[t]{2}{*}{0.156} \\
\hline & & $\mathrm{FNA}+\mathrm{P}$ & 80 & 5 & 6.3 & 43 & 53.8 & 6 & 7.5 & 16 & 20.0 & 10 & 12.5 & \\
\hline \multirow[t]{4}{*}{ Peripheral } & \multirow[t]{2}{*}{$5-10$} & FNA-P & 35 & 14 & 40.0 & II & 31.4 & 7 & 20.0 & 2 & 5.7 & I & 2.9 & \multirow[t]{2}{*}{0.772} \\
\hline & & $\mathrm{FNA}+\mathrm{P}$ & 15 & 7 & 46.7 & 5 & 33.3 & 1 & 6.7 & I & 6.7 & 1 & 6.7 & \\
\hline & \multirow[t]{2}{*}{$>10$} & FNA-P & 28 & 8 & 28.6 & 19 & 67.9 & 0 & 0.0 & 0 & 0.0 & I & 3.6 & \multirow[t]{2}{*}{0.634} \\
\hline & & $\mathrm{FNA}+\mathrm{P}$ & 23 & 8 & 34.8 & 12 & 52.2 & 2 & 8.7 & I & 4.3 & 0 & 0.0 & \\
\hline \multirow[t]{4}{*}{ Mixed } & \multirow[t]{2}{*}{$5-10$} & FNA-P & 32 & 6 & 18.8 & 5 & 15.6 & 5 & 15.6 & 9 & 28.1 & 7 & 21.9 & \multirow[t]{2}{*}{1.000} \\
\hline & & $\mathrm{FNA}+\mathrm{P}$ & 24 & 4 & 16.7 & 7 & 29.2 & 5 & 20.8 & 3 & 12.5 & 5 & 20.8 & \\
\hline & \multirow[t]{2}{*}{$>10$} & FNA-P & 39 & 8 & 20.5 & II & 28.2 & I & 2.6 & 9 & 23.1 & 10 & 25.6 & \multirow[t]{2}{*}{0.794} \\
\hline & & $\mathrm{FNA}+\mathrm{P}$ & 23 & 3 & 13.0 & 5 & 21.7 & 3 & 13.0 & 8 & 34.8 & 4 & 17.4 & \\
\hline \multirow[t]{2}{*}{ Sub-total } & & FNA-P & 774 & 144 & 18.6 & 264 & 34.1 & 83 & 10.7 & I7I & 22.1 & 112 & 14.5 & \\
\hline & & $\mathrm{FNA}+\mathrm{P}$ & 600 & 73 & 12.2 & 203 & 33.8 & 68 & 11.3 & 162 & 27.0 & 94 & 15.7 & \\
\hline Total & & & 1374 & 217 & 15.8 & 467 & 34.0 & $15 \mid$ & 11.0 & 333 & 24.2 & 206 & 15.0 & \\
\hline
\end{tabular}

Notes: Cytology was based on Bethesda classification criteria. Type I: specimen cannot be diagnosed or unsatisfactory; Type II: benign lesions; Type III: follicular or atypical follicular lesions that cannot be clearly defined; Type V: suspected malignant tumor; Type VI: malignant tumor.

Abbreviations: Micro, microcalcification; Coarse, coarse calcification; Peripheral, peripheral calcification; Mixed, mixed calcification (micro + coarse calcification); FNA-P, fine-needle aspiration without negative pressure; FNA+P, fine-needle aspiration with negative pressure.

Because the technique appears to have high sensitivity, US-FNA is used in diagnosing thyroid cancer. ${ }^{20}$ The certain characteristics of nodules are associated with thyroid cancer. Our results have shown the higher rates of thyroid carcinoma in microcalcifications and mixed micro plus coarse calcification of thyroid nodules. The data are similar to previous studies, in which microcalcifications are a highly specific sign of malignancy. ${ }^{21,22}$ Although the size may affect the positive rate, we have not found that the size of thyroid nodules has significant effects on the US-FNA cytology. By using a prospective randomized approach, the present study ensures the similar results of FNA-P and FNA+P techniques in the diagnosis of thyroid nodules, including thyroid cancer. Therefore, the negative pressure may not be necessary in ultrasound-guided fine needle aspiration of thyroid nodule.

In summary, our prospective randomized study has included 1374 patients with thyroid nodules diagnosed using FNA with or without negative pressure. There are no significant differences between FNA $+\mathrm{P}$ and FNA-P groups in type I, II, III, V and VI. Therefore, the negative pressure may not be necessary in ultrasound-guided fine needle aspiration of thyroid nodule. 


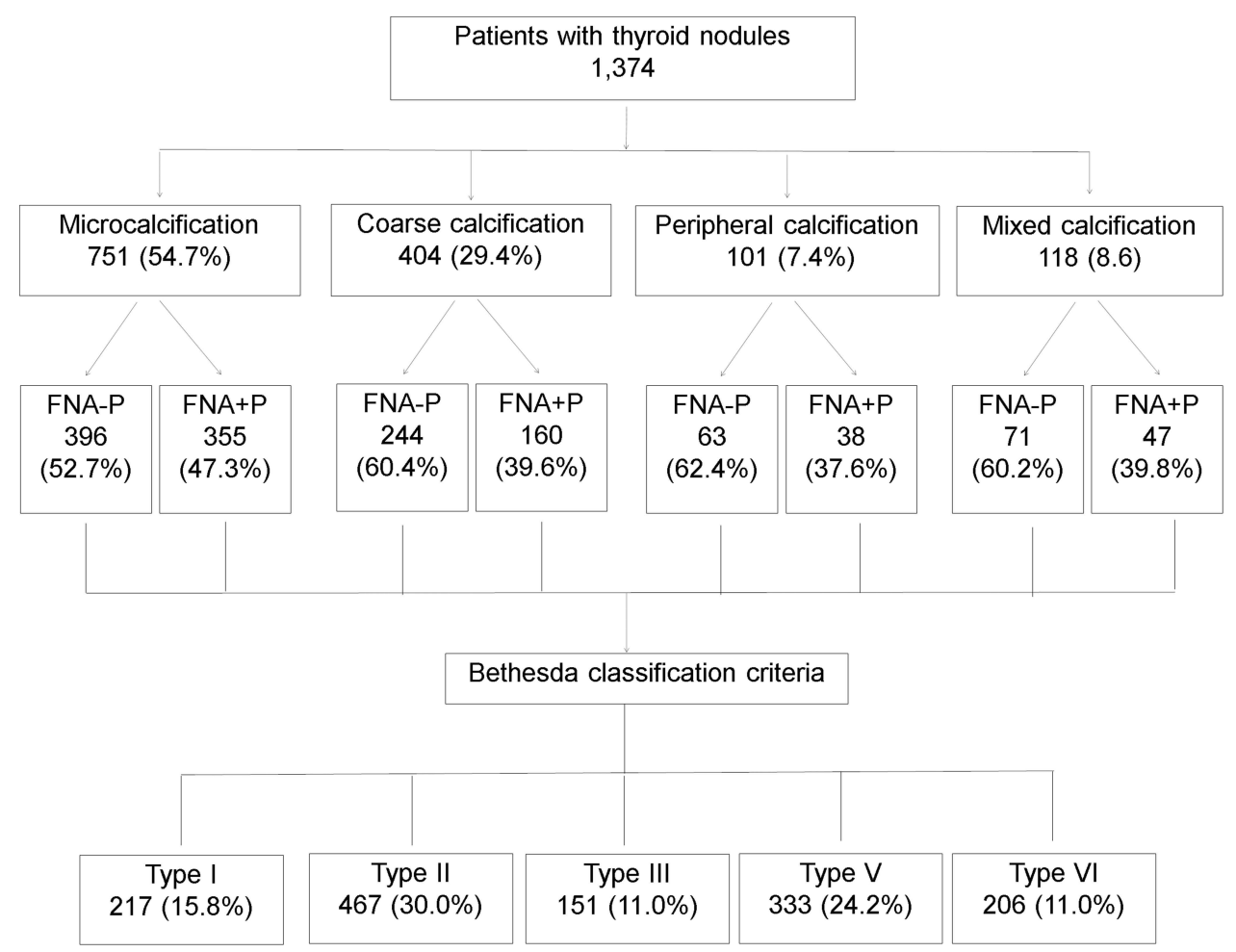

Figure 2 A summary of the study on thyroid nodules diagnosed by FNA-P and FNA+P.

\section{Acknowledgment}

The paper was supported by the Wenzhou Science and Technology Bureau (Grant No. Y20180610 and No. Y20180088).

\section{Disclosure}

The authors declare that they have no conflict of interest.

\section{References}

1. Dean DS, Gharib H. Epidemiology of thyroid nodules. Best Pract Res Clin Endocrinol Metab. 2008;22(6):901-911. doi:10.1016/j. beem.2008.09.019

2. Fisher SB, Perrier ND. The incidental thyroid nodule. CA Cancer J Clin. 2018;68(2):97-105. doi:10.3322/caac.21447

3. Hoang J. Thyroid nodules and evaluation of thyroid cancer risk. Australas J Ultrasound Med. 2010;13(4):33-36. doi:10.1002/j.22050140.2010.tb00177.x

4. Papini E, Guglielmi R, Bianchini A, et al. Risk of malignancy in nonpalpable thyroid nodules: predictive value of ultrasound and color-Doppler features. $J$ Clin Endocrinol Metab. 2002;87 (5):1941-1946. doi:10.1210/jcem.87.5.8504

5. Hadjisavva IS, Dina R, Talias MA, Economides PA. Prevalence of cancer in patients with thyroid nodules in the Island of Cyprus: predictive value of ultrasound features and thyroid autoimmune status. Eur Thyroid J. 2015;4(2):123-128. doi:10.1159/000430438

6. Chen W, Zheng R, Baade PD, et al. Cancer statistics in China, 2015. CA Cancer J Clin. 2016;66(2):115-132. doi:10.3322/caac.21338
7. Frates MC, Benson CB, Charboneau JW, et al. Management of thyroid nodules detected at US: society of radiologists in ultrasound consensus conference statement. Radiology. 2005;237(3):794-800. doi:10.1148/radiol.2373050220

8. Cooper DS, Doherty GM, Haugen BR, et al.; American Thyroid Association (ATA) Guidelines Taskforce on Thyroid Nodules and Differentiated Thyroid Cancer. Revised American Thyroid Association management guidelines for patients with thyroid nodules and differentiated thyroid cancer. Thyroid. 2009;19(11):1167-1214. doi: $10.1089 /$ thy. 2009.0110

9. Langer JE, Baloch ZW, McGrath C, Loevner LA, Mandel SJ. Thyroid nodule fine-needle aspiration. Semin Ultrasound CT MR. 2012;33(2):158-165. doi:10.1053/j.sult.2011.12.002

10. Castellana M, Piccardo A, Virili C, et al. Can ultrasound systems for risk stratification of thyroid nodules identify follicular carcinoma? Cancer Cytopathol. 2020;128(4):250-259. doi:10.1002/cncy.22235

11. Castellana M, Virili C, Paone G, et al. Ultrasound systems for risk stratification of thyroid nodules prompt inappropriate biopsy in autonomously functioning thyroid nodules. Clin Endocrinol (Oxf). 2020;93(1):67-75. doi:10.1111/cen.14204

12. Lee J, Kim BK, Sul HJ, Kim JO, Lee J, Sun WY. Negative pressure is not necessary for using fine-needle aspiration biopsy to diagnose suspected thyroid nodules: a prospective randomized study. Ann Surg Treat Res. 2019;96(5):216-222. doi:10.4174/astr.2019.96.5.216

13. Human D, Crawley F. Revised declaration of Helsinki. WMA will continue to revise policy as medicine and research changes. $B M J$. 2001;323:283-284.

14. Kobayashi K, Fujimoto T, Ota H, et al. Calcifications in thyroid tumors on ultrasonography: calcification types and relationship with histopathological type. Ultrasound Int Open. 2018;4(02):E45-E51. doi:10.1055/a-0591-6070 
15. Cibas ES, Ali SZ. The 2017 Bethesda system for reporting thyroid cytopathology. Thyroid. 2017;27(11):1341-1346. doi:10.1089/ thy. 2017.0500

16. Horvath E, Majlis S, Rossi R, et al. An ultrasonogram reporting system for thyroid nodules stratifying cancer risk for clinical management. J Clin Endocrinol Metab. 2009;94(5):1748-1751. doi:10.1210/jc.2008-1724

17. Whittle C, Garcia M, Horvath E, Slater J, Carrasco C. Thyroid microcalcifications in the absence of identifiable nodules and their association with thyroid cancer. J Ultrasound Med. 2019;38 (1):97-102. doi:10.1002/jum.14667

18. Alshaikh S, Harb Z, Aljufairi E, Almahari SA. Classification of thyroid fine-needle aspiration cytology into Bethesda categories: an institutional experience and review of the literature. Cytojournal. 2018;15:4. doi:10.4103/cytojournal.cytojournal_32_17
19. Santos JE, Leiman G. Nonaspiration fine needle cytology. Application of a new technique to nodular thyroid disease. Acta Cytol. 1988;32:353-356.

20. Li J, Wang Q, Wang L, et al. Diagnostic value of fine-needle aspiration combined with ultrasound for thyroid cancer. Oncol Lett. 2019;18:2316-2321.

21. Lee EK, Park YJ. Best achievements in clinical thyroidology in 2020. Endocrinol Metab (Seoul). 2021;36(1):30-35. doi:10.3803/ EnM.2021.103

22. Triggiani V, Guastamacchia E, Licchelli B, Tafaro E. Microcalcifications and psammoma bodies in thyroid tumors. Thyroid. 2008;18(9):1017-1018. doi:10.1089/thy.2008.0082
International Journal of General Medicine

\section{Publish your work in this journal}

The International Journal of General Medicine is an international, peer-reviewed open-access journal that focuses on general and internal medicine, pathogenesis, epidemiology, diagnosis, monitoring and treatment protocols. The journal is characterized by the rapid reporting of reviews, original research and clinical studies
Dovepress

across all disease areas. The manuscript management system is completely online and includes a very quick and fair peer-review system, which is all easy to use. Visit http://www.dovepress.com/ testimonials.php to read real quotes from published authors. 